\title{
Helping Faculty Meet New Pressures for Scholarly
}

\section{Writing}

\section{By Robert Boice}

California State University, Long Beach

The few reports of helping colleagues with scholarly writing in the faculty development literature have yet to address an important problem: What special problems await developers who try to implement programs for scholarly productivity on campuses where pressures for writing are new and probably unwelcome?

This paper provides one answer to that question with information about two groups new to pressures for scholarly writing: traditional faculty and librarians new to faculty status on regional university campuses with heavy demands for service including teaching.

The librarians in this study, like other faculty on traditionally teaching-oriented campuses, supposed that long-standing commitments to a service culture would conflict with the productivity culture often endorsed by the retention/promotion/tenure committees who decide faculty fates. These librarians chafed at prospects of being evaluated on the same terms as traditional faculty whose schedules seemingly permit more time for scholarship and research (e.g., Batt, 1985; Davidson, Thorson, \& Stine, 1983; DeBoer \& Culotta, 1987; Moran, 1984; Payne \& Wagner, 1984; Stoan, 1984). And these traditional faculty chafed at new and seemingly capricious demands to master the demanding habits of writing for publication amidst teaching loads twice those of doctoral campuses.

From To Improve the Academy: Resources for Student, Faculty, and Institutional Development, Vol. 7. Edited by J. Kurfiss, L. Hilsen, S. Kahn, M.D. Sorcinelli, and R. Tiberius. POD/New Forums Press, 1988. 
I report here the results of an ongoing program, now of two years' duration. Although my efforts include systematic help for faculty on teaching and collegiality, I concentrate here on the particularly challenging task of facilitating writing. The program began with two goals: The first goal consisted of visiting faculty and librarians in their work settings to observe work pressures and changes in coping styles firsthand. This strategy involved little more than usual survey methods for getting to know new faculty in traditional departments (Crawley, Atkins, \& Gruen, 1987; Sorcinelli, 1986; Turner \& Boice, 1987), except that visits were frequent and regular. In this instance, information about faculty and librarians was expected to reveal a sense of which developmental strategies could facilitate coping with new pressures for writing. Specifically, I wondered if faculty and librarians, despite their claims of busyness and negativism, could be helped to find the time and willingness neessary to writing.

The second goal came from initial observations of library faculty, a group typically neglected by faculty developers. I suspected that librarians might profit in learning to see traditional faculty as colleagues with similar strengths and problems.

\section{Methods}

\section{Subjects}

The librarians depicted here worked at a large regional university where they were full members of the faculty. They were paid on a salary schedule identical to that of the faculty, had ranks equivalent to those of the professoriat, were eligible for tenture and sabbaticals, and had representation in the university's senate, councils, and committees on the same basis as that of the traditional faculty. These librarians were members of the union representing the faculty at large and were by a negotiated agreement expected to work "an average of $\mathbf{4 0}$ hours in a seven-day period."

The librarians studied here represented each of the four academic ranks. All of them volunteered to be visited on a "spot observations schedule" by the author and to maintain daily records of their work activities for a period of at least one year. The study began with a sample of 12 library faculty, all of them veterans, all of them tenured. Midway through the study two newly hired and untenured librarians were added to the group; at that time three veteran librarians were dropped in response to indications of lack of interest in the program.

The comparison group of 12 traditional faculty members came from two large regional universities, four of them from the same campus as the 
librarians studied. This sample of faculty members was selected from a larger collection of observations on the basis of gender (there were four males in the librarian group) and years in service (there were only two librarians with less than 10 years of work experience). All the traditional faculty members in the sample came from campuses where pressures for scholarship, research, and publishing were seen as relatively new and often unwelcome.

\section{Enlisting Participants}

Recruitment of both samples in this study was aided by the support of administrators: essentially, the dean or the library director agreed to invite the observer/faculty developer to speak about the nature and aims of the project, make supportive comments about the potential values of the project, and work behind the scenes to coax (but not coerce) individuals to volunteer.

\section{Self-Report Forms}

Both groups completed simple self-report sheets each week; traditional faculty and librarians drew arrows on such sheets to indicate duration of time spent on particular activities (see Boice, Scepanski, \& Wilson, 1987, for more details). Activities were coded using the kinds of taxonomies listed at the top of the sample sheets.

The observer (i.e., author), in his weekly, unannounceed visits to participants, provided an important check on the objectivity of these selfreports. Upon appearing in the midst of whatever the librarian or professor was doing, the observer typically began by noting two things: 1) his own classification and ratings of the ongoing activity and 2) if the participant was maintaining the self-report form. Most participants reported that maintaining verified self-reports on a daily basis led to very different accounts of workweeks than they had previously reported in more retrospective surveys.

\section{Tracking Participants}

Except for a few instances when either participants or the observer were away from campus due to illness or vacation, most library faculty and traditional faculty were observed weekly over a 52-week period. Each such period preceded and carried beyond the bounds of a fall and a spring semester. Each weekly visit lasted from 10-20 minutes. 
Potential times for visits came from previous self-report forms that indicated regularly schedduled activities, from information solicited about plans for coming weeks, and from administratively issued schedules.

Tracking visits were planned, where practical, to sample the typical range of on-campus activities for each participant. For example, in visits where participants were actively working wwith library users (e.g., providing reference service), the observer remained unobtrusive. During visits where participants had lulls in activity, the observer encouraged them to talk about their work by listening patiently and asking a few open-ended questions. On occasional, preplanned visits, all members of a sample group were asked a "question of the week" (e.g., "was spring vacation a time when you planned to do scholarly writing?"). Other visits to activities such as classroom teaching led to systematic ratings and advice which were shared wwith individual participants.

This format provided a strong sense of rapport between either faculty or librarians and the observer; although some librarians and faculty began as skeptics, all eventually expressed a fondness for the meetings and the support and interest conveyed in them. Many participants used these interactions for purposes of personal development.

\section{Results and Discussion}

\section{Practicality and Reliability of the Methodology}

Access to both sample groups for weekly observations was regular. The typical weekly investment of the observer's time in these observations (and in occasional failures to find some individuals) was about 4.5 hours for librarians and 6.0 hours for other faculty members. The difference in weekly investment owed to the location of the librarians in one building. An important point to be drawn from this information is that both groups were accessible and cooperative.

Except in dimensions of rating the subjective aspects of on-going activities, judgments about the kinds of activities and their location in time by faculty and the observer produced nearly perfect agreement. This result supports the contention that direct observational checks can enhance the reliability of faculty's self-reports of workweeks (Boice, 1987).

\section{Do Librarians Have Less Time for Scholarly Writing?}

The failure rate among the librarians in complying with observer requests for weekly self-report sheets - one in 12 (i.e., 8 percent) - is some- 
what better than noncompliance rates of 14 percent found in the larger faculty sample from which the 12 faculty depicted here were drawn.

Figure 1 depicts the workweeks of the 11 librarians who completed tracking sheets during the 52 weeks of study. These reports confirmed indications in the literature (Moran, 1984) that librarians generally put in 40-hour workweeks on campus.

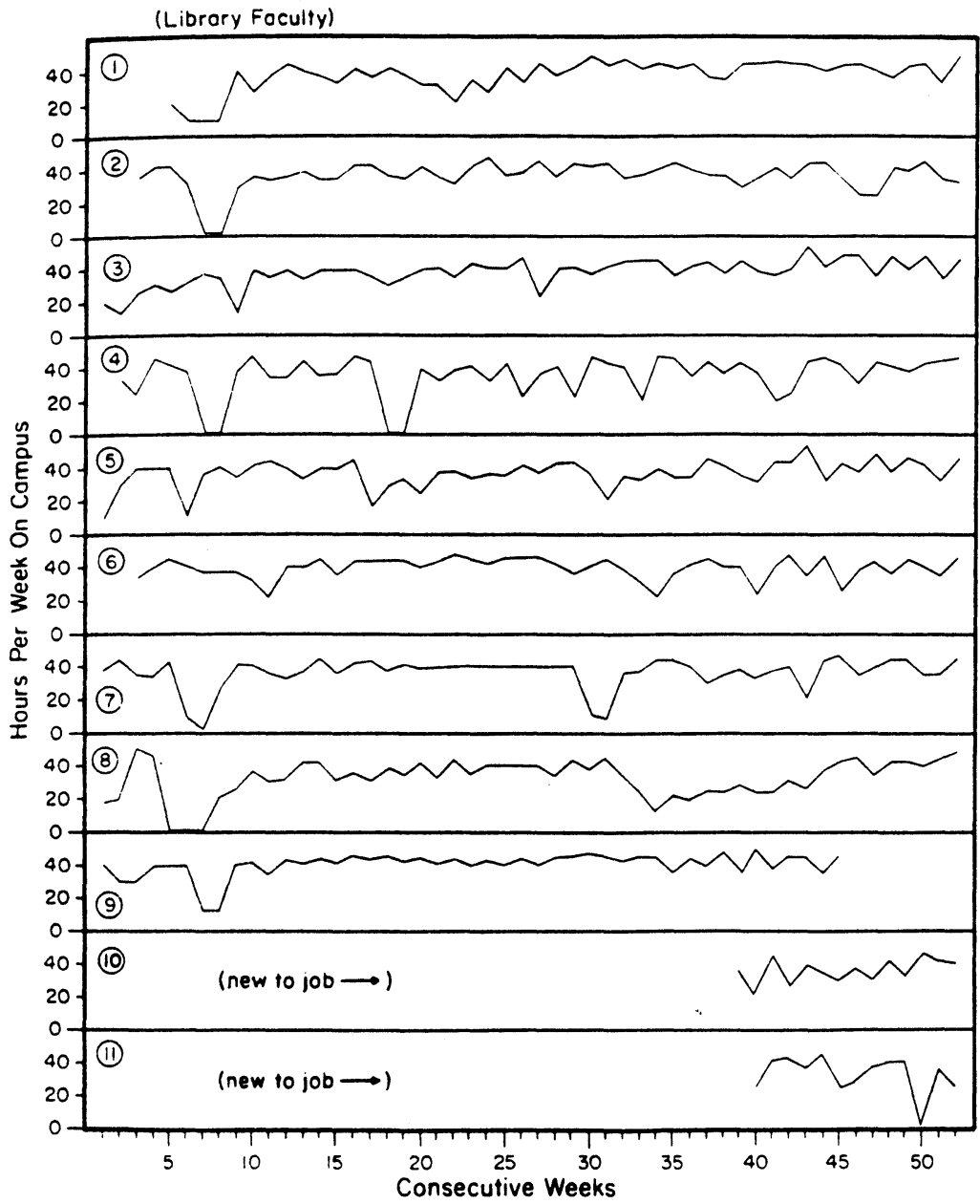

FIGURE 1. Individual graphs representing the workweeks of 11 librarians who regularly submitted self-report sheets during their participation in the project. 
Figure 2 confirms the contention of librarians that they put in longer workweeks, on campus, than do the faculty. The 12 faculty members who completed timely and usable self-reports showed a pattern of on-campus workweeks much shorter than that of the librarians.

At first glance faculty members seemed to have time for research and scholarship whereas librarians did not.

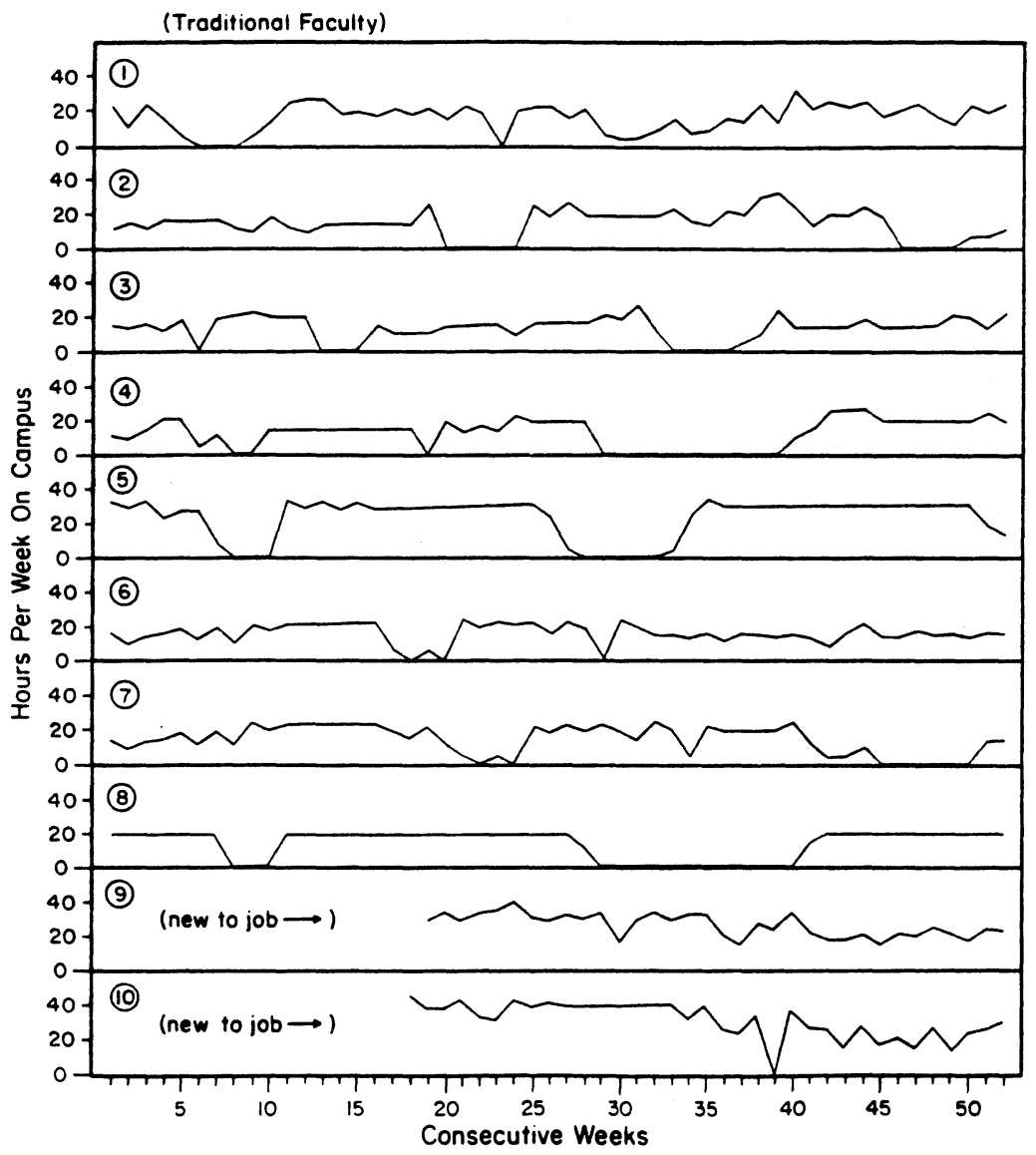

FIGURE 2. Individual graphs representing the workweeks of 10 faculty who regularly submitted self-report sheets during their participation in the project. 


\section{Complexities in the Search for Sufficient Time}

Despite the initial appearance of available time, the traditional faculty members consistently claimed that they were too busy for scholarly writing. In addition to their report of an overall mean of around 25 hours per week on campus during semesters, all faculty (cf. only two librarians) indicated varying amounts of work-related activity carried out at home. Usual activities self-reported by faculty in home offices were grading papers and tests, preparing lectures and syllabi, and reading in preparation for lectures. If these unverified reports are given even partial credence, the workweeks of the faculty more closely approach those of librarians.

This is the point where reports of academicians coping with new pressures for research and scholarship usually end-with confirmation of claims for too little time in the midst of already overloaded schedules. But the tracking procedure used here suggested the need for further examination.

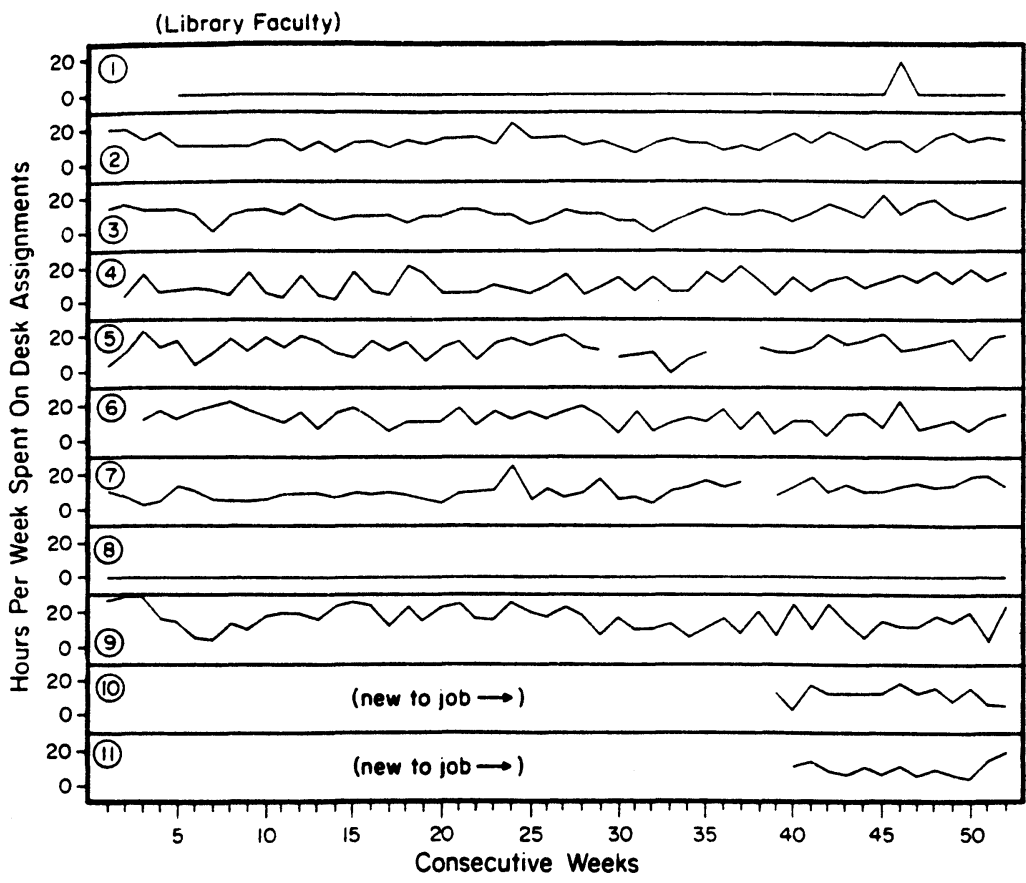

FIGURE 3. Individual graphs of desk assignments for the 11 librarians. 
Weekly visits with both librarians and faculty members across a variety of activities frequently found them doing things that were spontaneously described by them as nonessential or inefficient. So, for example, faculty members might have had regular visitors during office hours who chatted for two hours about current events or sports; just as often faculty sat, during office hours, reading newspapers or magazines, waiting for students, or engaging in other relatively unproductive activities. Librarians often engaged in similar activities, so long as more structured tasks such as desk assignments did not intervene.

One way of assessing the availability of time for scholarship began with an examination of requirements for certain core activities. Figure 3 shows the mean time spent by librarians depicted in Figure 1 on desk assignments. These self-reported weekly means included time at the reference desk, at a separately staffed information desk, or at a bibliographic instruction station other than the classroom (a for-credit library skills program on campus required students to consult with librarians and other staff). An interesting aspect of Figure 3, a portrayal of the reference and consultation workweek of the librarians, is its resemblance to core workweeks of faculty members. Both cores hovered around 15-20 hours per week, for required desk assignments on one hand and for lecture time plus office hours on the other.

Of course, both groups typically added other, generally obligatory assignments to these cores. Both groups attended committee meetings. Faculty members often worked with students on individual projects. Librarians often worked with individual students and faculty in fulfilling information needs, for example by doing online searching, and they frequently lectured to classes. When these other essential activities are added to the reference and consultation activity, the resultant patterns of at least 25-28 hour workweeks for these librarians began to resemble the on-campus workweeks of traditional faculty as inferred from Figure 2.

Even when blocks of time for additional assignments of librarians (e.g., collection development) and of faculty (e.g., serving as a referee for a scholarly journal) were added, this deeper analysis of the tracking data produced a surprise. Both groups still seemed to have discretionary time, at least parts of which might be devoted to scholarship. When asked about this possibility, almost every person in both groups gave the same answer: the occasional breaks of 30 minutes or so, in an otherwise busy schedule, were not sufficient for scholarship. Writing, they pointed out in near unison, requires large blocks of undisrupted time.

I was tempted, in the face of these earnest arguments, to concede. The librarians and faculty under study here were already doing a conscientious and competent job in the service sphere. Should we expect more? 
One answer is that scholarly writing is now a required activity for both groups. A second answer is that scholarship can enhance the kinds of services librarians and faculty provide (e.g., as better informed scholars with a timely knowledge of new developments in their disciplines).

\section{The Initial Attempt at Facilitating Writing in the Midst of Busy Schedules}

The minority of faculty members in this sample who managed to get writing done helped provide a clue about solutions for busyness. The most effficient and productive writers simply wrote during the brief openings in their service-oriented schedules. Equally important, they made writing a priority activity, one during which distractions such as phone calls were minimized.

This potential solution was presented to both groups in the form of brief workshops held during the first two months of their participation in this project.

\section{Short-Term Results: Did Faculty and Librarians Make Use of Available Time?}

All 24 of the subjects in the present study listened cooperatively to the arguments for writing in the midst of their service obligations and busy schedules, but few in either group pursued the idea seriously during the first six months of the study.

Eight people from the faculty group began writing occasionally during their on-campus workweeks and over the first half year of participation; four wrote somewhat regularly. Only five of the librarians approached writing occasionally amidst other campus activities during the equivalent time span; none wrote regularly. But neither group, in the first six months, produced writing on campus that promised to meet the expectations of their campus administrators (of about one article per year published in refereed journals).

\section{Why Most Faculty Members and Librarians Didn't Write Productively in the Short Run}

Reasons why both librarians and faculty were generally unproductive writers replicated results found elsewhere. Reported inhibitions to scholarly writing include fears of failure or perhaps success, cruel reviewers, and competition for limited space in journals. But the fact remains that some librarians and some faculty did publish in the short run. 
Why is it that most of the individuals observed here persisted in old patterns of non-productivity?

One reason may be momentum. I suspected that an investment longer than half a year may be needed to change long-standing habits of devoting workweeks almost exclusively to service for students and others in the academic community. A second reason derived from another dimension of habit. Faculty and librarians unused to scholarship reported feeling unprepared and unqualified to begin writing; they seemed to need time to acclimate to the idea of generating useful ideas and publishable prose.

Table 1 summarizes the comments of both groups about why they were making little sustained effort at writing in the short run. All the comments were recorded during weekly observations, some as responses to "questions of the week," the rest as spontaneous comments. Two salient features of that table are: 1) the similarity between librarians and faculty members (except for one dimension) in reasons for not writing, and 2) the persistence of these faculty in using busyness as an impediment. The single reason that distinguished the two groups was the belief by librarians that writing inevitabley undermines teamwork in providing service valued by them. Faculty, in contrast, seemed to place little value on teamwork.

Table 1 seems to provide useful insights about reasons for not writing in the short run. First, maladaptive beliefs about scholarly writing were maintained beyond my expectations. Second, unproductive writers may have been stymied by a lack of ideas and of cultural support; the tradition-

\section{TABLE 1}

\section{Summary of Reasons Given in the Short Run by Both Groups for Not Doing Scholarly Writing}

\begin{tabular}{|c|c|c|}
\hline \multirow[b]{2}{*}{ Reason } & \multirow{2}{*}{$\begin{array}{l}\text { der of Reason } \\
\text { Librarians }\end{array}$} & \multirow{2}{*}{$\begin{array}{l}\text { Terms of Popularity } \\
\text { Faculty Members }\end{array}$} \\
\hline & & \\
\hline Too busy to write & 1 & 1 \\
\hline Service to patrons/students comes first & 2 & 2 \\
\hline $\begin{array}{l}\text { Writing necessitates poor teamwork } \\
\text { re service }\end{array}$ & 3 & $L^{*}$ \\
\hline Good writing requires large blocks of time & 3 & 3 \\
\hline $\begin{array}{l}\text { Only original, significant thoughts } \\
\text { merit publication }\end{array}$ & 5 & 4 \\
\hline $\begin{array}{c}\text { The editorial process is cruel and } \\
\text { unfair/fears of failure }\end{array}$ & 6 & 5 \\
\hline Writing is inherently aversive & 7 & 6 \\
\hline
\end{tabular}

*Never mentioned by traditional faculty members 
al service-oriented culture of both groups provides little encouragement or "continuing education" for scholarly writing. Becoming a productive writer may have required more than finding time.

\section{Signs of Success in the Longer Run}

Here again, first glances proved misleading. At the end of an entire year of participation in the faculty development programs aimed, in part, at facilitating scholarly writing, neither faculty nor librarians showed substantial increases over activity levels at midpoint. Thus, the initial impression was that the extra time and participation (of extending the study to a full year) had little impact. Except for the moderate levels of writing activity shown by a few faculty and librarians from the outset and by the two new members of each group (all of whom were hired with clear expectations of writing), levels of involvement during workweeks seemed to remain fairly constant throughout the study period.

\section{TABLE 2}

Ratings (Based on Periodic Self-Statements of Librarians) of Readiness* for Scholarly Writing Over the Course of One Year of Observations

\begin{tabular}{cllllllll} 
& \multicolumn{8}{c}{ Periodic Instances of Questions } \\
Librarian & 1 & 2 & 3 & 4 & 5 & 6 & 7 & 8 \\
\hline$\# 1$ & 2 & 2 & 1 & 3 & 4 & 3 & 4 & 4 \\
$\# 2$ & 1 & 1 & 1 & 1 & 1 & 1 & 1 & 1 \\
$\# 3$ & 1 & 1 & 1 & 1 & 5 & 5 & 5 & 5 \\
$\# 4$ & 5 & 1 & 1 & 5 & 5 & 5 & 5 & 5 \\
$\# 5$ & 2 & 1 & 1 & 1 & 3 & 3 & 3 & 3 \\
$\# 6$ & 2 & 1 & 2 & 1 & 3 & 3 & 4 & 4 \\
$\# 7$ & 2 & 2 & 2 & 2 & 5 & 5 & 5 & 5 \\
$\# 8$ & 1 & 1 & 1 & 1 & & & & \\
$\# 9$ & 1 & 1 & 1 & 2 & 3 & 4 & 4 & 4 \\
$\# 10$ & newly hired $\Rightarrow$ & 2 & 6 & 6 & 6 & 4 \\
$\# 11$ & newly hired $\Rightarrow$ & 2 & 4 & 6 & 4 & 6 \\
\hline X & 1.9 & 1.2 & 1.2 & 1.9 & 3.5 & 3.7 & 3.7 & 3.7
\end{tabular}

*Readiness ratings followed this system: 1 = no plans for writing and reject writing as appropriate for librarians; $2=$ no plans for writing, but accept writing as appropriate; 3 = states specific plans for writing, but no writing being done; $4=$ specifies ongoing, preliminary efforts at writing (e.g., doing literature search; $5=$ doing writing, but off-campus only; $6=$ doing writing on and off campus. 
Closer examination of subtle indices, however, provided a more optimistic picture of helping faculty and librarians cope with pressures for scholarship. While, for instance, the rank-ordering of complaints about being pressured to write (Table 1 ) did not change, the frequency of such objections dropped by half from the 6-month to the 12-month points of observation for both groups. Moreover, these complaints were issued to the observer in less strident, challenging fashion than during the first half of the study year.

Table 2 and 3 depict another, more direct means of arguing for subtle but significant changes in the ways faculty and librarians eventually began coping with pressures for scholarship. Although a few faculty and librarians (all of them veterans of campuses where they had not been expected to publish) steadfastly maintained refusals to accept scholarly writing as part of their job descriptions, their colleagues generally showed noticeable shifts in attitudes and practices related to writing by the second half of the year of study. Four faculty and four librarians had moved two

\section{TABLE 3}

Ratings (Based on Periodic Self-Statements of Faculty) of Readiness* for Scholarly Writing Over the Course of One Year of Observations

\begin{tabular}{lllllllll}
\multicolumn{10}{c}{ Periodic Instances of Questions About Status as Writer } \\
Faculty Member 1 & 2 & 3 & 4 & 5 & 6 & 7 & 8 \\
\hline$\# 1$ & 6 & 6 & 6 & 6 & 6 & 6 & 6 & 6 \\
$\# 2$ & 1 & 2 & 2 & 2 & 2 & 3 & 3 & 4 \\
$\# 3$ & 2 & 1 & 1 & 1 & 1 & 1 & 1 & 1 \\
$\# 4$ & 1 & 2 & 2 & 2 & 2 & 3 & 4 & 4 \\
$\# 5$ & 1 & 2 & 1 & 2 & 2 & 2 & 2 & 3 \\
$\# 6$ & 5 & 5 & 4 & 4 & 5 & 4 & 5 & 5 \\
$\# 7$ & 1 & 1 & 2 & 3 & 4 & 5 & 4 & 5 \\
$\# 8$ & 2 & 2 & 3 & 3 & 3 & 4 & 4 & 4 \\
$\# 9$ & newly hired $\Rightarrow$ & & 2 & 2 & 3 & 4 \\
$\# 10$ & newly hired $\Rightarrow$ & & 4 & 5 & 5 & 5 \\
\hline$X$ & 2.4 & 2.6 & 2.6 & 2.9 & 3.1 & 3.5 & 3.7 & 4.1
\end{tabular}

*Readiness ratings followed this system: 1 = no plans for writing and reject writing as appropriate for librarians; 2 = no plans for writing, but accept writing as appropriate; 3 = states specific plans for writing, but no writing being done; $4=$ specifies ongoing, preliminary efforts at writing (e.g., doing literature search; $5=$ doing writing, but off-campus only; $6=$ doing writing on and off campus. 
steps in the "readiness" scale used in Tables 2 and 3; they had generally advanced from skepticism or inactivity to preliminary writing activities. Three faculty and four librarians progressed even farther, moving from skepticism and/or inactivity to regular writing sessions.

The causes for these general shifts in readiness for writing seemed to include time and momentum. Both groups seemed to need opportunities to rethink initial skepticism. Both seemed to move deliberately in acquiring new habits of thinking about themselves as writers and of practicing writing.

Causes for the shifts in readiness seen in Tables 2 and 3 may also have owed to factors beyond the faculty development programs. The appearance of new faculty (who brought positive attitudes and active plans for writing with them) may have stimulated senior colleagues to change.

A reminder that faculty development programs rarely work as expected came in collecting the evidence summarized in Tables 2 and 3. Most of the faculty and librarians active in preliminaries or actual writing persisted in expressions of distaste for writing; the changes in scholarly productivity, at least in the time span studied here, were not accompanied by equivalent changes in attitudes. The faculty and librarians involved felt adamant about never accepting the pressure for writing productivity as willingly as they accepted service commitments.

In fact, a striking bit of resistance to the faculty development programs employed here can be seen in the reluctance of either group to write regularly on campus, during workweeks. Perhaps membershsip on campuses with strong service traditions means that writing, even when the task is accepted to the point of regular practice, is kept psychologically serparate from service activities including teaching. A typical comment of writers in both groups was that while writing may be worthwhile, it should not be done on the job, at taxpayer expense.

As observations continue, changes may be seen in the attitudes and practices of these librarians and faculty. I plan to check for even further involvement in writing, including indices of success in publishing. What the library director and $\mathbf{I}$ hope to do next will incorporate a program of outreach services (mainly literature searches) with ongoing efforts including writing. We expect two benefits in this broadening: an energizing effect that may generalize to things like writing and an increased appreciation of librarians by traditional faculty.

In sum, many librarians and faculty can make significant strides toward coping with new pressures for scholarship in just a year. What $\mathrm{I}$ hope to see next is that campuses stceped in service traditions can blend those commitments with the product cultures imported from doctorate granting campuses. 


\section{References}

Batt, F. (1985) Faculty status for academic librarians: Justified or just a farce? In P. Spyers-Duran \& T.W. Mann, Jr. (Eds.), Issues in academic librarianship (pp. 115-128). Westport, CT: Greenwood Press.

Boice, R. (1987). Is released time an effective component of faculty development programs? Research in Higher Education , 26, 311-326.

Boice, R., Scepanski, J.M, \& Wilson, W. (1987). Librarians and faculty members: Coping with pressures to publish. College \& Research Libraries, 48, 494-503.

Crawley, A., Atkins, S., \& Gruen, C. (1987, October). Faculty quality of life : Catalyst for change. Paper presented at the Twelfth Annual Conference of the Professional and Organizational Development Network in Higher Education, Kerrville, Texas.

Davidson, R., Thorson, C. C., \& Stine, D. (1983). Faculty status for librarians: Querying the troops. College \& Research Libraries, 44, 414420.

DeBoer, K., \& Culotta, W. (1987). The academic librarian and faculty status in the 1980's: A survey of the literature. College \& Research Libraries, 48, 215-223.

Moran, B. B. (1984). Academic libraries: The changing centers of colleges and universities. Washington, D.C.: Association for the Study of Higher Education.

Payne, J., \& Wagner, J. (1984). Librarians, publication, and tenure. College \& Research Libraries, 45, 133-139.

Sorcinelli, M. D. (1986). Career goals of faculty: Future trends and directions. Journal of Staff, Program \& Organizational Development, 4(1), 9-12.

Stoan, S. K. (1984). Research and library skills: An analysis and interpretation. College \& Research Libraries, 45, 99-109.

Turner, J. L., \& Boice, R. (1987). Starting at the beginning: The concerns and needs of new faculty. In J. Kurfiss, L. Hilsen, L. Mortensen, and E. Wadsworth (Eds.), To inprove the academy (pp. 41-55). Stillwater, OK: New Forums Press, Inc. 